\section{Gene bill still controversial}

Munich. Austrian academics and industrialists have welcomed a revision of the draft gene bill that would simplify safety requirements and reduce the administrative burden on researchers. But controversy continues because the bill would legislate not only on safety but also on social and ethical aspects of applications such as gene diagnosis and therapy. Critics say existing laws should be amended to cover such areas.

Austria's Socialist health minister, Michael Ausserwinkler, revised the bill following protests that it was 'hyperbureaucratic and antiresearch'. Scientists argued that the approval procedure would delay experiments as it used too many unscientific criteria. Other interest groups attacked the bill as scientifically and ethically confused.

Erhard Busek, the science minister, argued that the failure of Germany's gene law (see Nature 363, 481; 1993), on which Austria modelled its bill, showed that such restrictive legislation is unworkable: Ausserwinkler needs Busek's support because the cabinet must approve the bill unanimously.

The bill's major concession is that researchers would not have to seek case-bycase authorization for experiments falling into the lowest of the four designated safety grades: 'low or no risk to humans and the environment': they need only be registered. Higher risk experiments would be authorized within 90 days. A national committee for biological safety and the health ministry's scientific committee on genetic engineering would assess safety levels. In Germany, such low-risk experiments still require individual authorization, although this is being hotly debated in parliament.

Safety requirements for the release of transgenic plants into the environment remain similar to those in other countries: field trials would need to be carried out in stages, each approved by a safety commission. Procedures will, however, probably be simplified for experiments already carried out elsewhere or involving release of plants considered as "easy to recover". The revised bill drops the question of liability in the event of environmental damage.

Still controversial, however, is Ausserwinkler's plan to include in the bill provisions on social and ethical aspects of gene diagnosis and therapy. Politicians across Franz Vranitzky's coalition government disagree over whether such a comprehensive gene law makes sense.

Some argue that existing laws cover many applications of genetic engineering, particularly in medicine. They believe it would be better simply to amend such laws to take new techniques into account, as most European countries have done. Legislating for such things as gene therapy within a safety law, they claim, could hinder progress by implying a level of danger that does not exist.

The bill would ban germ-line gene therapy. It would allow somatic gene therapy for serious hereditary diseases and cancer but not for cosmetic purposes, and create a ministerial committee - along the lines of the US National Institutes of Health's Recombinant Advisory Committee - to authorize applications. A local ethics commission at each clinic would approve protocols

Amendment of existing drug laws would make more sense, says Nikolaus Zacherl, administrative director of the Institute for Molecular Pathology in Vienna: "The health ministry is only interested in making a name for itself and in assuming a pioneering role in the world with this new gene law."

The revised bill relaxes a requirement that patients should approve any medical analysis using genetic techniques. This would have put the onus for technical decisions on non-experts. Patients would still need to consent to genetic analyses used to diagnose hereditary diseases or to identify genetic predispositions. But routine methods for monitoring therapy, such as HLA cell-typing during leukaemia treatment, would be exempted.

Patients diagnosed with genetic disorders would also have to attend genetic consultations. Christine Mannhalter, director of the department of molecular genetics at $\mathrm{Vi}$ enna's General Hospital, complains that it is difficult to imagine who would provide the service because Austria has no training programme in human genetics.

Other parts of the bill would forbid employers and insurance companies to use genetic data to screen applicants.

Robert Unterhuber

\title{
Earthlings interfere in extraterrestrial search
}

Santa Cruz, California. Electromagnetic radiation from Earth is interfering with the controversial \$104-million hunt by the US National Aeronautics and Space Administration (NASA) for little green men.

NASA started its ten-year Search for Extraterrestrial Intelligence programme (SETI) last October, after years of wrangling with legislators who called it a waste

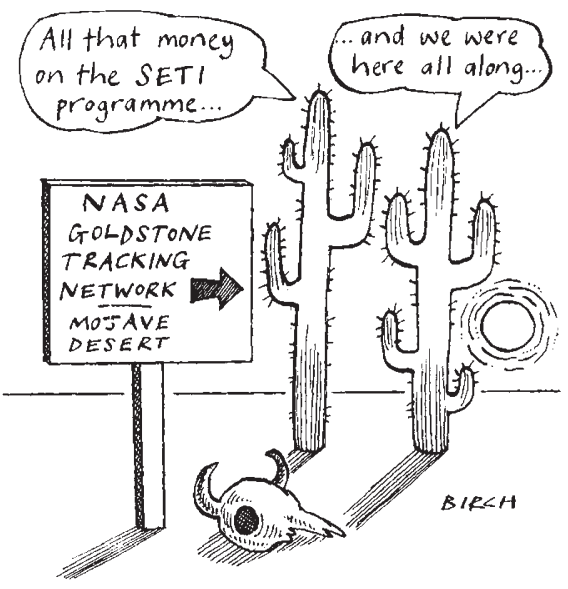

of taxpayers' money. At least eight radiotelescopes in the United States and Australia are expected to take part, scanning millions of radio frequencies for signs of intelligent life. Some will home in on stars most likely to have habitable planets (Targeted Search). Others will sweep the heavens indiscriminately (Sky Survey).

Last autumn the Targeted Search team, led by Jill Tarter, logged more than twohundred hours of observations of 25 stars using the Arecibo Observatory in Puerto Rico. They found the incidence of false alarms, caused by radio interference, to be much higher than expected. NASA will take steps next year to avoid such a waste of scarce and expensive observation time. It will equip each radiotelescope with a followup device, which would continue to analyse a puzzling signal at higher resolution; meanwhile, the rest of the equipment would scan the same star at other frequencies.

The agency will also begin observing SETI signals interferometrically, by combining signals from the same star detected simultaneously by observatories far apart. Software would eliminate interference from
Earth, identified as signals that do not stay fixed with respect to the stars as the Earth rotates.

The Sky Survey part of SETI has not encountered any more false alarms than it expected. It operates from the 34-metre radiotelescope at NASA's Goldstone tracking network in the Mojave Desert in California, and the frequencies it scans are free of interference.

News of the unexpected interference in the Targeted Search programme was announced at last week's International Astronomical Union conference on the search for extraterrestrial life.

At last year's meeting, scientists from the former Soviet Union were enthusiastic about conducting joint SETI searches with NASA. This year, only three Russian scientists, all on sabbatical in the United States, took part; two invited researchers did not turn up. "The United States is rich enough to afford SETI," explains Vladimir S. Strelnitski, a former vice-president of a Russian SETI commission, who now works at the $\mathrm{Na}$ tional Air and Space Museum in Washington, "Russia isn't." 